\title{
Long term compliance with California's Smoke-Free Workplace Law among bars and restaurants in Los Angeles County
}

\author{
M D Weber, D A S Bagwell, J E Fielding, S A Glantz
}

See end of article for authors' affiliations

\section{Correspondence to:} Mark D Weber, 3530 Wilshire Boulevard, 8th Floor Los Angeles, CA 90010, USA; mweber@dhs.co.la.ca.us

Received

10 October 2002

Accepted 3 May 2003

\begin{abstract}
Objective: To assess long term compliance with the California Smoke-Free Workplace Law in Los Angeles County freestanding bars and bar/restaurants.

Design: Population based annual site inspection survey of a random sample of Los Angeles County freestanding bars and bar/restaurants was conducted from 1998 to 2002.

Main outcome measures: The primary outcomes of interest were patron and employee smoking. The secondary outcomes of interest were the presence of ashtrays and designated outdoor smoking areas. Results: Significant increases in patron non-smoking compliance were found for freestanding bars (45.7\% to $75.8 \%, p<0.0001)$ and bar/restaurants $(92.2 \%$ to $98.5 \%, p<0.0001)$ between 1998 and 2002. Increases in employee non-smoking compliance were found for freestanding bars $186.2 \%$ to $94.7 \%, p<0.0003$ ) and bar/restaurants $(96.5 \%$ to $99.2 \%, p<0.005)$.

Conclusions: This study provides clear evidence that the California Smoke-Free Workplace Law has been effective at reducing patron and employee smoking in Los Angeles County bars and restaurants. Recommendations include educational campaigns targeted to freestanding bar owners and staff to counter perceptions of lost revenue, more rigorous enforcement, and more severe penalties for repeat violators such as alcohol licence revocation. Policymakers can enact smoke-free restaurant and bar policies to protect employees and patrons from secondhand smoke, confident that these laws can be successfully implemented.
\end{abstract}

S econdhand smoke (SHS) causes fatal and non-fatal health end points including heart disease, lung and nasal sinus cancer, sudden infant death syndrome, childhood asthma, bronchitis and pneumonia, middle ear infection, and low birth weight. ${ }^{1-4}$ SHS accounts for up to 65000 non-smoker American deaths annually and is the third leading preventable cause of death. ${ }^{45}$

The workplace is a primary source of SHS exposures among adult non-smokers in the USA. ${ }^{6}$ Bar and restaurant workers have higher levels of exposure than other occupations $\mathrm{s}^{7-10}$ and, correspondingly, elevated risk of lung and other respiratory cancers. ${ }^{8}$ Bartenders working in single room facilities have almost 10 times the SHS exposure as bartenders working in multi-room and restaurant facilities. ${ }^{111}$

The California Smoke-Free Workplace Law (Assembly Bill (AB) 13, enacted as California Labor Code LC 6404.5) took effect on 1 January 1995 and prohibits smoking in almost all places of employment. Bars, taverns, and gaming clubs were given until 1 January 1998 to comply with LC 6404.5.

As of January 2003, major cities, states, and countries around the world, including New York, Boston, Chicago, Denver, Pittsburgh, Delaware, Hong Kong, New Zealand, Australia, Sweden, Ireland, and Thailand, are considering or are ending smoking in bars and restaurants. These localities are likely to face difficulty passing or implementing legislation due to claims of catastrophic economic impact on the hospitality industry, and allegations that the law is being universally disobeyed in places with current laws such as California. Numerous published studies have demonstrated that smoke-free ordinances have no effect or a positive effect on hospitality industry revenue in California ${ }^{12-14}$ and elsewhere. ${ }^{12-18}$ The findings presented here provide the first published data demonstrating long term compliance with the California Smoke-Free Workplace Law in bars and restaurants, refuting the allegation that the law is being disobeyed.

\section{METHODS}

Provisions of California Labor Code 6404.5

LC 6404.5 states "no employer shall knowingly or intentionally permit, and no person shall engage in, the smoking of tobacco products in an enclosed space at a place of employment". ${ }^{19}$ In addition, the law requires the posting of clear and prominent "No smoking" signs at each business entrance (businesses are responsible for obtaining signs). Bars, restaurants, taverns, and clubs exempted from LC 6404.5 include: businesses that are solely owner operated, hotel/motel banquet rooms (except while food and beverages are being served), private smokers' lounges, as well as employee break rooms and small businesses under limited conditions.

LC 6404.5 is enforced by local agencies designated by local governing bodies (for example, health, fire, and police departments). Business owners and patrons in violation of LC 6404.5 are subject to fines of $\$ 100$ for the first violation and up to $\$ 500$ for the third violation within a year. After three violations within one year, cases may be referred to the California Occupational Safety and Health Administration that can levy fines up to $\$ 70000$. Citations may be appealed through a process similar to traffic violations.

\section{California State compliance efforts}

The California Department of Health Services (DHS) Tobacco Control Section (TCS) initiated a statewide compliance campaign in July 1997, six months before the implementation

Abbreviations: $A B C$, Alcohol Beverage Control; DHS, Department of Health Services; EHD, Environmental Health Division; SHS, secondhand smoke; TCS, Tobacco Control Section; TCP, Tobacco Control and Prevention Program; TEMC, Tobacco Education Media Campaign; TEP, Tobacco Enforcement Program 
date of the law. ${ }^{20}$ The campaign included mailings of educational materials to 35000 bar, restaurant, and gaming club owners and print advertisements such as listing popular bars and restaurants throughout the state that publicly supported the law. TCS also ran a television and radio campaign focusing on the smoke-free workplace law. From January 1998 through June 2000, TCS ran a total of 1111 television, radio and print advertisements in Los Angeles County.

BREATH, a programme of the American Lung Association of the East Bay and funded by the TCS, was created to support the state implementation of smoke-free bars and restaurants by local agencies. BREATH developed a project to: inform and educate business owners and patrons about the law; collect and evaluate economic impact data; provide legal interpretations and enforcement models; develop local media to counter tobacco industry campaigns; and train local tobacco control advocates. $^{21}$

\section{Los Angeles County compliance efforts}

To promote compliance with the California Smoke-Free Workplace Law in Los Angeles County bars and restaurants, the County Department of Health Services Tobacco Control and Prevention Program (TCP) initiated a comprehensive compliance campaign in 1998. The campaign, which was based on the Center for Disease Control's Best practices for comprehensive tobacco control programs, ${ }^{22}$ focused on monitoring, education, and enforcement.

Monitoring efforts included an annual on-site survey of bars and restaurants to assess compliance. Educational activities included: disseminating a newsletter and educational pamphlet to bar and restaurant owners; conducting a radio campaign; and obtaining local news coverage. Enforcement activities included: coordinating BREATH sponsored officer trainings; providing technical assistance; operating a telephone and website based complaint system; sending warning letters, educational materials, and "No smoking" signs to establishments; and forwarding alleged violations to local enforcement agencies. TCP has no legal authority to enforce LC 6404.5 and plays a supportive role to the enforcement agencies in the 88 cities within Los Angeles County.

\section{Bar and restaurant compliance survey}

A survey of Los Angeles County bars and restaurants was initiated by TCP in 1998 to monitor compliance with the California Smoke-Free Workplace Law. The population based annual cross sectional survey samples $8-10 \%$ of the approximately 9000 Los Angeles County bars and restaurants licensed with the California Alcohol Beverage Control (ABC).

$\mathrm{ABC}$ establishments were categorised into two on-sale alcohol licence types: those that reside within restaurants (hereafter referred to as "bar/restaurants"); and those that have minimal meal service or kitchen facilities (hereafter referred to as "freestanding bars"). Establishment types were created by assigning each of the five relevant alcohol licence types to either the bar/restaurant (for example, type 41 -on-sale beer and wine eating place) or freestanding bar category (for example, type 48-on-sale general (beer, wine, and spirits) public premises (non-eating)).

A stratified (by type of establishment) random sample of bar/restaurants and freestanding bars was selected each year. In addition, oversampling of freestanding bars was utilised to increase the precision of their compliance estimates as they represent only about $18 \%$ of all establishments. Beginning in 2000, the degree of oversampling of freestanding bars was increased to permit sufficient sample sizes for analyses stratified by licence type (for example, in $199828 \%$ of all establishments sampled were freestanding bars in comparison to $67 \%$ in 2002). Also beginning in 2000, the sample was stratified by geographical area and establishment type to enhance its representativeness and increase the precision of the compliance estimates.
Survey participation rates by year were as follows: $1998-84.3 \% \quad(611 / 725) ; 1999-82.8 \% \quad(682 / 824) ; 2000-$ $81.1 \%(831 / 1025) ; 2001-82.1 \%(846 / 1030) ;$ and $2002-88.1 \%$ (1010/1146). Reasons for non-response in 2002 were: establishment closed-62.5\% (85/136); out of business-18.4\% (25/136); wrong address-8.1\% (11/136); closed for remodelling-2.2\% (3/136); and other-8.8\% (12/136). No establishments refused site inspections.

TCP contracted with the DHS Environmental Health Division (EHD) to conduct the annual site inspection survey. EHD inspectors were selected because of their expertise in monitoring and enforcing health code in bars and restaurants (although they do not have authority to enforce LC 6404.5), and legal authority to access all areas of these establishments. Each year the site inspections were unannounced and were conducted by approximately 130 EHD inspectors ( 65 teams of two for safety) over a single weekend (Friday and Saturday) in June or July, between the hours of $6 \mathrm{pm}$ to $10 \mathrm{pm}$.

Beginning in 1999, inspectors attended a half day training approximately one month before the survey date. The TCP trainer distributed and reviewed a site inspection protocol that included an overview of key components of the law and instructions on how to complete the survey instrument. Partner and site observation assignments were made after the training.

Beginning in 2000, the site inspection protocol was revised and emphasised the reliability and validity of the survey. For example, the TCP trainer instructed inspectors to complete site inspections immediately upon entering establishments to avoid alerting owners/patrons of their presence and precipitating the extinguishing of cigarettes. The trainer also highlighted data collection problems observed in previous surveys and presented findings from prior years to demonstrate the importance of their efforts.

Each year the survey instrument (see appendix on $e \mathrm{TC}$ ) consisted of site observation items and a brief interview. The site inspection items that corresponded to the requirements of the law included: "Are clear and prominent 'No smoking' signs posted at each entrance?"; "Are there any patrons smoking inside the premises?"; and "Are there any employees smoking inside the premises?" Inspectors also checked for the presence of ashtrays (a proxy indicator for smoking) and designated separate outdoor smoking areas. Beginning in 2001, EHD inspectors interviewed management and staff about whether they were in favour of repealing the California Smoke-Free Workplace Law and, if so, reasons for favouring repeal (for example, "The law has hurt business" or "Smoking should be the owner's choice, not the government's").

Compliance was defined as no observed patron or employee smoking inside bar/restaurants and freestanding bars, and the presence of "No smoking" signs posted at entrances by health inspectors. The detection of smoke odour, presence of cigarette smoke, and visible cigarette butts or packs, although recorded by inspectors, did not constitute non-compliance.

The Cochran-Armitage trend test, using SAS software, ${ }^{23}$ was used to assess the statistical significance of compliance changes between 1998 and 2002. SUDAAN software ${ }^{24}$ was used to conduct all tests for differences between two independent proportions presented in the Results and Discussion sections. Separate analyses were conducted for bar/ restaurants and freestanding bars. To make the freestanding bar category comparable across survey years, analyses were restricted to three alcohol licence types common to all survey years. Final analysis sample sizes were as follows: 1998 $(\mathrm{n}=611) ; 1999(\mathrm{n}=561) ; 2000(\mathrm{n}=632) ; 2001(\mathrm{n}=696)$; and $2002(\mathrm{n}=760)$. Sampling weights were used in the statistical analyses to account for the differential selection probability of the sampled bar/restaurants and freestanding bars. Weights were assigned such that they were inversely proportional to the selection probability (for example, a freestanding bar, which because of oversampling was three times 
Table 1 California Smoke-Free Workplace Law compliance among bar/restaurants by survey year

\begin{tabular}{|c|c|c|c|c|c|c|c|}
\hline \multirow[b]{2}{*}{ Indicators } & \multirow{2}{*}{$\begin{array}{l}1998 \\
\% * \text { (numberf) }\end{array}$} & \multirow{2}{*}{$\begin{array}{l}1999 \\
\% \text { (number) }\end{array}$} & \multirow{2}{*}{$\begin{array}{l}2000 \\
\% \text { (number) }\end{array}$} & \multirow{2}{*}{$\begin{array}{l}2001 \\
\% \text { (number) }\end{array}$} & \multirow{2}{*}{$\begin{array}{l}2002 \\
\% \text { (number) }\end{array}$} & \multicolumn{2}{|c|}{ Cochran-Armitage trend test } \\
\hline & & & & & & Z Statistic & $\mathrm{p}$ Value \\
\hline No smoking patrons & $92.2(390 / 423)$ & $94.4(384 / 407)$ & $95.4(361 / 378)$ & $98.8(392 / 397)$ & $98.5(246 / 250)$ & 5.04 & 0.0001 \\
\hline No smoking employees & $96.5(380 / 394)$ & $99.0(401 / 405)$ & $98.8(369 / 373)$ & $99.1(392 / 396)$ & 99.2 (247/249) & 2.83 & 0.0047 \\
\hline Ashtrays & $8.9(36 / 406)$ & 7.9 (32/407) & $7.4(28 / 377)$ & $6.2(24 / 396)$ & $2.2(6 / 250)$ & -3.16 & 0.0016 \\
\hline Outdoor smoking area & $39.4(153 / 388)$ & $39.6(161 / 407)$ & $44.6(168 / 377)$ & $46.4(183 / 395)$ & $43.6(109 / 250)$ & 1.99 & 0.0466 \\
\hline
\end{tabular}

* Sample weights were used to adjust the proportions.

†Weighted sample size. Numbers rounded to the nearest integer.

\begin{tabular}{|c|c|c|c|c|c|c|c|}
\hline \multirow[b]{2}{*}{ Indicators } & \multirow{2}{*}{$\begin{array}{l}1998 \\
\% * \text { (numbert) }\end{array}$} & \multirow{2}{*}{$\begin{array}{l}1999 \\
\% \text { (number) }\end{array}$} & \multirow{2}{*}{$\begin{array}{l}2000 \\
\% \text { (number) }\end{array}$} & \multirow{2}{*}{$\begin{array}{l}2001 \\
\% \text { (number) }\end{array}$} & \multirow{2}{*}{$\begin{array}{l}2002 \\
\% \text { (number) }\end{array}$} & \multicolumn{2}{|c|}{ Cochran-Armitage trend test } \\
\hline & & & & & & Z Statistic & $\mathrm{p}$ Value \\
\hline No smoking patrons & $45.7(74 / 162)$ & $55.9(85 / 152)$ & $67.0(169 / 253)$ & $67.3(201 / 298)$ & $75.8(386 / 510)$ & 7.44 & 0.0001 \\
\hline No smoking employees & $86.2(131 / 152)$ & $92.0(138 / 150)$ & $89.5(225 / 252)$ & $94.1(280 / 298)$ & $94.7(481 / 508)$ & 3.60 & 0.0003 \\
\hline Ashtrays & $63.6(98 / 154)$ & $52.0(79 / 152)$ & $40.5(102 / 252)$ & $38.5(114 / 296)$ & $30.5(155 / 508)$ & -7.82 & 0.0001 \\
\hline Outdoor smoking area & $33.3(50 / 150)$ & $29.1(44 / 151)$ & $37.7(95 / 252)$ & $45.0(134 / 298)$ & $44.4(225 / 508)$ & 3.75 & 0.0002 \\
\hline
\end{tabular}

*Sample weights were used to adjust the proportions.

†Weighted sample size. Numbers rounded to the nearest integer.

more likely to be selected than a bar/restaurant, would receive a weight of $1 / 3$ or 0.333 ).

\section{RESULTS}

\section{Compliance survey}

The weighted proportions and sample sizes for four site inspection items by survey year (1998 through 2002) are in tables 1 and 2 for bar/restaurants and freestanding bars. Patron smoking compliance in bar/restaurants increased significantly from $92.2 \%$ to $98.5 \%(\mathrm{p}<0.0001)$, and patron compliance from $45.7 \%$ to $75.8 \%(p<0.0001)$ in freestanding bars. Employee compliance in bar/restaurants increased from $96.5 \%$ to $99.2 \%(p<0.005)$, and from $86.2 \%$ to $94.7 \%$ $(\mathrm{p}<0.0003)$ in freestanding bars.

The presence of ashtrays declined in bar/restaurants from $8.9 \%$ to $2.2 \%$ ( $p<0.002$ ), and decreased from $63.6 \%$ to $30.5 \%$ $(\mathrm{p}<0.0001)$ in freestanding bars, mirroring the increase in patron compliance. There were also significant increases in designated outdoor smoking areas for bar/restaurants from $39.4 \%$ to $43.6 \% \quad(\mathrm{p}<0.05)$, and from $33.3 \%$ to $44.4 \%$ $(\mathrm{p}<0.0002)$ in freestanding bars. The increase in outdoor smoking areas, particularly among freestanding bars, was substantially smaller than the increase in compliance indoors $(11.1 \%$ v $33.1 \%)$, indicating that outdoor smoking areas were not simply replacing smoking indoors.

Alcohol licence-type specific analyses indicated that patron smoking compliance rates differed among freestanding bars. For example, in 2002 compliance was $90.4 \%$ for licence type 40 (beer only), approaching the same level observed for restaurant/bars, and $72 \%$ for type 48 (beer, wine and spirits) $(\mathrm{p}<0.0001)$. Compliance was also significantly higher in freestanding bars that displayed "No smoking" signs versus those that did not $(70.0 \% \vee 52.2 \%, \mathrm{p}<0.0003)$. Moreover, compliance differences between freestanding bars with and without signs were more pronounced in the first three years of the survey. Compliance with and without signs for each year was: $1998-47.8 \%$ v 42.9\%; $1999-60.7 \%$ v 44.7\%; 2000$72.2 \%$ v 46.8\%; 2001-70.2\% $v$ 61.9\%; and 2002-77.5\% $v$ $73.4 \%$. Compliance did not significantly differ in bar/ restaurants with and without signs $(94.2 \% \vee 97.1 \%, p=0.07)$.

Interviews conducted with bar management/staff after compliance observations show that $50.5 \%$ of freestanding bars favoured repealing the LC 6404.5 compared to only $14.9 \%$ of bar/restaurants $(\mathrm{p}<0.0001)$. Among freestanding bar management/staff who favoured repealing the law, 65.6\% agreed with the statement that "The law has hurt business" and $54.5 \%$ agreed with "Smoking should be the owner's choice, not the government's". Compliance was significantly lower in freestanding bars that favoured repeal in comparison to those that did not $(57.4 \% v 88.5 \%, \mathrm{p}<0.0001)$. In contrast, compliance did not significantly differ in bar/restaurants that favoured repeal $(96.1 \% v 99.1 \%, \mathrm{p}=0.19)$.

\section{DISCUSSION}

By 2002, four years after the California Smoke-Free Workplace Law began protecting workers and patrons in bars and restaurants, compliance with the law is high in Los Angeles County, reaching nearly $99 \%$ in bar/restaurants and $76 \%$ in freestanding bars.

Notwithstanding the substantial increase in patron nonsmoking in freestanding bars from $45.7 \%$ to $75.8 \%$, compliance remains below the $98.5 \%$ found for bar/restaurants. Unpublished results from the City of San Francisco Tobacco Free Project have also shown similar findings; patron smoking compliance for 2002 was $80.0 \%$ for freestanding bars and $98.2 \%$ for bar/restaurants (A Hrushow, personal communication, 2 August 2002).

One possible reason for the disparity between patron non-smoking in freestanding bars and restaurant/bars was the impact of a statewide tobacco industry sponsored public relations campaign that targeted freestanding bars. ${ }^{25}$ This campaign claimed that freestanding bars would experience catastrophic economic losses and smokers' and business owners' rights would be violated. ${ }^{25}$ Findings from the bar management/staff interview presented above suggest that the campaign was effective. Management/staff from freestanding bars were almost six times more likely to favour repealing LC 6404.5 compared to those from bar/restaurants. In addition, among freestanding bar management/staff who favoured repealing the law, the majority agreed with the statements that "The law has hurt business" and "Smoking should be the owner's choice, not the government's", the same messages used in the tobacco industry's campaign. Lower levels of support for the law may have reduced freestanding bar management/staff's willingness to prohibit patron smoking, accounting in part for the lower compliance. 
Review of Los Angeles County compliance campaign Monitoring efforts

There were several elements of TCP's monitoring system that enhanced its effectiveness. TCP, as part of the DHS, was able to recruit large numbers of qualified inspectors, critical to inspect 1000 establishments spread over 4000 square miles. Localities that do not have ready access to health inspectors may consider alternative observers such as staff posing as bar patrons.

Access to a complete database of licensed establishments is necessary to achieve a representative sample. Unlike commercially available business lists that typically have inclusion criteria and infrequent updates, ABC maintains a database of all state licensed alcohol establishments, updated daily to include information such as suspensions, revocations, and transfers of ownership.

The representative sample should also include all relevant alcohol licence types. For example, beginning in 1999 the number of licence types representing freestanding bars surveyed was increased from three to seven to provide a more representative sample. The analyses were repeated utilising all seven licence types to assess the generalisability of the findings. Compliance trends for all indicators listed in table 2 were significant, corroborating the results based on three licence types.

The time interval between purchase of the database and the compliance checks is another important consideration. To minimise potential non-response because of inaccurate establishment listings, TCP purchases the database about two months before the compliance survey, allowing time for developing the sampling plan, sample selection, and assigning establishments to EHD inspectors. TCP's approximate two month time period between purchase and survey resulted in a relatively high average response rate of $84 \%$. However, in 2002, $18.4 \%$ of the non-response was still the result of establishments being out of business at the time of the survey, suggesting the need for even shorter time periods. Verifying the establishment hours of operation and addresses is also important as $62.5 \%$ of the non-response was the result of establishments being closed for business (not out of business), and $10.3 \%$ for reasons including wrong address and closed for remodelling.

The day and time the survey is conducted is a potential source of bias. EHD restricted inspectors' availability to a single weekend with site inspections to be completed by $10 \mathrm{pm}$. However, the San Francisco Tobacco Free Project study conducted their bar compliance survey seven days a week between the hours of $6 \mathrm{pm}$ and midnight, and no significant differences were found for time of day or day of week (A Hrushow, personal communication, 2 August 2002). A related issue is the time of year the survey is conducted (TCP conducts the survey every summer during June or July). However, because of the year round moderate temperature in southern California, the season the survey is conducted in is unlikely to have a substantial impact on compliance.

Although compliance rates presented above were based on site observations, TCP also collects compliance information from the county smoking complaint hotline and website. From 1 January 1998 through 31 December 2002, 1687 complaints had been registered with TCP. Approximately 52\% of the complaints were logged in 1998 (880), 17\% in 1999 (289), $15 \%$ in 2000 (251), 9\% in 2001 (156), and 7\% in 2002 (111).

LC 6404.5 citations and prosecutions represent another important source of compliance information. In 2000, the Los Angeles Tobacco Enforcement Program (described below) began systematically recording citation information for the City of Los Angeles. Citations by year were as follows: 2000159, 2001-147, and 2002-109 (N Manzanilla, personal communication, 17 January 2003). The agreement of compliance results obtained from multiple sources of information, including site observations, complaints, and citations, provide clear evidence that compliance with the California SmokeFree Workplace Law is increasing in Los Angeles County.

\section{Education efforts}

Since 1990, TCS has managed the Tobacco Education Media Campaign (TEMC) to reduce tobacco use through cutting edge advertising (television, radio, billboards, transit, and print). ${ }^{20}$ In late 1997, TEMC began focusing media messages on smoke-free bars and restaurants with the majority of advertisements placed in the three largest media markets in the state-Los Angeles, San Diego, and San Francisco.

The campaigns were effective in promoting public awareness and support of the California Smoke-Free Workplace Law in Los Angeles County ${ }^{20}{ }^{25}$ and likely contributed to the rapid compliance gains observed. Studies conducted in other localities such as New York City and Southern Australia also demonstrate high levels of public support for smoke-free restaurants. $^{26-28}$

\section{Enforcement efforts}

In 1998, the Fire Department was designated as the enforcement agency for LC 6404.5 in the City of Los Angeles, and personnel were initially instructed to educate bar staff and patrons and issue warnings instead of citations for violations. The Tobacco Enforcement Program (TEP) was created in 2000 by the Los Angeles City Attorney's Office to coordinate active enforcement and prosecution of LC 6404.5 and other tobacco control laws. TEP began a systematic effort to reduce non-compliance in bars and restaurants through rapid investigation of complaints, issuing citations instead of warnings, and vigorous prosecution of violators. Because of these efforts, the number of citations issued tripled from 50 in 1999, to 159 in 2000. In 2002, 43 cases were filed with the Los Angeles City Attorney's office against bar owners found in violation of LC 6404.5 (N Manzanilla, personal communication, 30 January 2003). Because $40 \%$ of freestanding bars and bar/restaurants licensed in the County of Los Angeles are located within the City of Los Angeles, these enforcement efforts may have contributed to the recent compliance gains in the county. Compliance could be further improved if the other 87 cities would initiate more rigorous enforcement programmes.

In addition to implementing the above "macro" level enforcement efforts, instituting "micro" level enforcement activities could also benefit compliance efforts. Alcohol licence-type specific findings presented above for freestanding bars indicated that patron smoking compliance rates differed by over $18 \%$ between several licence types. Compliance was also significantly higher in freestanding bars that displayed "No smoking" signs and these differences were more pronounced in the first three years of the survey, suggesting that their presence appears to be important during the initial years of law implementation. Compliance did not significantly differ in bar/restaurants displaying signage suggesting that posting signs may no longer be relevant for bar/restaurants, many of which have been complying with LC 6404.5 since 1995. ${ }^{25}$ Enforcement efforts aimed at improving freestanding bar signage compliance (especially during initial law implementation) and targeted to problematic freestanding bar alcohol licence types may enhance compliance gains.

\section{Conclusion}

This study provides clear evidence that the California SmokeFree Workplace Law has been effective at reducing patron and employee smoking in Los Angeles County bars and restaurants. Although compliance in freestanding bars is lower than in bar/restaurants, it has been increasing by almost $8 \%$ a year and if this rate continues, compliance will reach the levels observed in bar/restaurants in approximately three years. However, maintaining this relatively rapid rate will likely 


\section{What this paper adds}

There have been no published studies documenting long term compliance with California's Smoke-Free Workplace Law in bars and restaurants. Unpublished studies have had research and sampling design problems, limiting their representativeness and interpretability.

This methodologically rigorous, population based study provides the first published data of long term compliance with a smoke-free bar and restaurant law. The study provides evidence that the law has been effective at reducing patron and employee smoking in bars and restaurants. These results supply evidence that other cities, states, and countries can use to facilitate adoption of their own smoke-free laws.

require vigorous education and enforcement efforts. Educational campaigns targeted at freestanding bar owners and staff (especially those who serve beer, wine, and spirits) to counter the inaccurate perception of lost revenue are recommended. Greater enforcement efforts, including timely investigation of complaints, active citing of patron and, particularly, owner violators, vigorous prosecution, and more severe penalties for repeat violators such as alcohol licence revocation are also recommended. Policymakers can enact smoke-free restaurant and bar policies to protect employees ${ }^{29}$ and patrons from secondhand smoke confident that these laws can be successfully implemented.

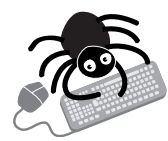

To see the appendix visit the Tobacco Control website - www.tobaccocontrol.com/supplemental

\section{ACKNOWLEDGEMENTS}

Dr Weber and Ms Bagwell were supported by California Department of Health Services Grants 89-97908 and TCS 01-19. Professor Glantz's work is supported by National Cancer Institute Grant CA-61021. We want to acknowledge and thank the following individuals: Cynthia A Harding, MPH, Catherine Condon, MPH, and Tracy G Doyle, MPH, for providing helpful comments on earlier versions of this manuscript; and Arturo Aguirre and his staff for conducting the site inspections.

\section{Authors' affiliations}

M D Weber, D A S Bagwell, J E Fielding, Los Angeles County Department of Health Services, Los Angeles, California, USA

S A Glantz, Center for Tobacco Control Research and Education,

University of California, San Francisco, San Francisco, California, USA

\section{REFERENCES}

1 US Department of Health and Human Services. The health consequences of involuntary smoking. A report of the Surgeon General, 1986. Rockville, Maryland: Public Health Service, Centers for Disease Control, 1986. (DHHS Publication No (CDC) 87-8398.)

2 US Environmental Protection Agency. Respiratory health effects of passive smoking: lung cancer and other disorders. Washington, DC: Office of Health and Environmental Assessment, 1992. (Publication No $\mathrm{EPA} / 600 / 6-90 / 006 \mathrm{~F}$.)
3 National Research Council. Committee on passive smoking environmental tobacco smoke. Measuring exposures and assessing health effects. Washington DC: National Academy Press, 1986.

4 National Cancer Institute. Health effects of exposure to environmental tobacco smoke: the report of the California Environmental Protection Agency. Smoking and Tobacco Control Monograph No 10. US Department of Health and Human Services, Public Health Service, National Institutes of Health, National Cancer Institute, 1999. (NIH Publication No 99-4645.)

5 Glantz SA, Parmley WW. Passive smoking and heart disease. Circulation 1991;83:1-12.

6 Brownson RC, Hopkins DP, Wakefield MA. Effects of smoking restrictions in the workplace. Annu Rev Public Health 2002;23:333-48.

7 Hammond S. Exposure of U.S. workers to environmental tobacco smoke. Environ Health Perspect 1999;107(suppl 2):329-40.

8 Siegel $\mathbf{M}$. Involuntary smoking in the restaurant workplace. A review of employee exposure and health effects. JAMA 1993;270:490-3.

9 Miesner EA, Rudnick SN, Hu FC, et al. Particulate and nicotine sampling in public facilities and offices. J Air Pollut Control Assoc 1989:39:1577-82.

10 Jenkins R, Counts R. Occupational exposure to environmental tobacco smoke: results of two personal exposure studies. Environ Health Perspect 1999; 107(suppl. 2):341-8.

11 Maskarinec MP, Jenkins RA, Counts RW, et al. Determination of exposure to environmental tobacco smoke in restaurant and tavern workers in one US city. J Exp Anal Environ Epidemiol 2000;10:36-49.

12 Glantz SA, Charlesworth A. Tourism and hotel revenues before and after passage of smoke-free restaurant ordinances. JAMA 1999;281:191118.

13 Glantz SA, Smith LRA. The effect of ordinances requiring smoke-free restaurants on restaurant sales. Am J Public Health 1994;84:1081-5.

14 Glantz SA, Smith LRA. The effect of ordinances requiring smoke-free restaurants and bars on revenues: a follow-up. Am J Public Health 1997;87: 1687-93.

15 Sciacca J, Ratliff $M$. Prohibiting smoking in restaurants: effects on restaurant sales. Am J Health Promotion 1998;12:176-84.

16 Bartosch WJ, Pope GC. The economic effect of smoke-free restaurant policies on restaurant business in Massachusetts. J Public Health Manag Pract 1999;5:53-62.

17 Wakefield $M$, Siahpush M, Scollo $M$, et al. The effect of a smoke-free law on restaurant business in South Australia. Aus NZ J Public Health 2002;26:375-81

18 Scollo M, Lal A, Hyland A, et al. Review of the quality of studies on the economic effects of smoke-free policies on the hospitality industry. Tobacco Control 2003:12:13-20.

19 California Labor Code Section 6400-6413.5. URL: http://www.leginfo.ca.gov/cgi-bin/ displaycode? section=lab\&group $=06001-07000 \&$ file $=6400-6413.5$

20 Wingo C, Kiser D, Boschert T, et al. Eliminating smoking in bars, restaurants, and gaming cubs in California: The California Smoke-Free Workplace Act. Sacramento, California: California Department of Health Services, Tobacco Control Section, November 2001.

21 Kiser D, Boschert T. Eliminating smoking in bars, restaurants, and gaming clubs in California: BREATH, the California smoke-free bar program. J Public Health Policy 2001 ;22:81-7.

22 Centers for Disease Control and Prevention. Best practices for comprehensive tobacco control program - August 1999. Atlanta, Georgia: US Department of Health and Human Services, Centers for Disease Control and Prevention, Office on Smoking and Health, August 1999.

23 SAS Institute Inc. SAS/STAT user's guide, version 8. Cary, North Carolina:SAS Institute Inc, 1999.

24 Software for the Statistical Analysis of Correlated Data (SUDAAN) for PCs. Release 8.0. Research Triangle Park, North Carolina: Research Triangle Institute, 2001

25 Magzamen S, Glantz SA. The new battleground: California's experience with smoke-free bars. Am J Public Health 2001;91:245-52.

26 Hyland A, Cummings KM. Consumer response to the New York City Smoke-Free Air Act. J Public Health Manag Pract 1999:5:28-36.

27 Miller C, Wakefield M, Kriven S, et al. Evaluation of smoke-free dining in South Australia: support and compliance among the community and restaurateurs. Aust NZ J Public Health 2002;26:38-44.

28 Wakefield $M$, Roberts L, Miller C. Perceptions of the effect of an impending restaurant smoking ban on dining-out experience. Prev Med 1999:29:53-6.

29 Eisner MD, Smith AK, Blanc PD. Bartenders' respiratory health after establishment of smoke-free bars and taverns. JAMA 1998;280:190914 